\section{(跑) RMA}

\title{
EDITORIAL
}

\author{
Andrés D. Izeta
}

Director Revista del Museo de Antropología, IDACOR-CONICET - Museo de

Antropología, Facultad de Filosofía y Humanidades, Universidad Nacional de Córdoba. E-mail: aizeta@ffyh.unc.edu.ar

En este primer número del año 2018 presentamos veinte artículos originales que se suman los ya disponibles en la Revista en formato de acceso abierto. Nueve de ellos corresponden a la Sección Arqueología; cinco corresponden al área de la Antropología Biológica, dos a la Sección Museología; y cuatro a Antropología Social.

En el primer trabajo de la Sección Arqueología Ramiro Barberena, Augusto Tessone, María Nella Quiroga, Florencia Gordón, Carina Llano, Alejandra Gasco, Jimena Paiva y Andrew Ugan presentan los primeros resultados de ecología isotópica regional para el extremo norte de la provincia del Neuquén (Argentina), información clave para la reconstrucción de cambios ecológicos y paleodietas humanas a través del tiempo. Continúa María Paula Barros quien presenta el análisis y la discusión acerca de la producción de módulos laminares sobre dos rocas ampliamente utilizadas en la subregión pampa húmeda, como son la ortocuarcita del Grupo Sierras Bayas y la ftanita. Con ello se busca indagar acerca de cuáles fueron los criterios técnicos tenidos en cuenta, tanto para la preparación de los núcleos, como para su explotación. Emiliano Mange, Maitén Irma Di Lorenzo y Lucio González Venanzi presenta el análisis de los materiales faunísticos del sitio Tembrao, ubicado en un pequeño valle al pie de la meseta de Somuncurá (sur de la provincia de Río Negro) con cronologías asignables al Holoceno tardío. Lorena Grana realiza una revisión crítica de la evolución y estado actual de los análisis diatomológicos en cuestiones arqueológicas, principalmente incluyendo los estudios latinoamericanos. Anne Gustavsson discute y pone en dialogo las prácticas y la trayectoria científica del arqueólogo Eric Boman (1867-1924) y los modos que ha sido recordado por la historia disciplinar. Brenda Irene Oxman y Rodolphe Hoguin exploran la relación entre los cambios ambientales producidos en la Puna Seca Argentina durante el periodo 12 000- 4000 años AP y su incidencia en la variabilidad observada en las estrategias adaptativas desarrolladas por los grupos humanos en la tecnología lítica. Norma Ratto, Alejandro Rodríguez González, Mara Basile, Francisco J. Pérez Torrado y José L. Fernández Turiel presentan un primer modelo de cálculos volumétricos para estimar la tasa de incisión en función del desalojo del material piroclástico de la quebrada de Las Papas a lo largo de
4200 años, y estimar cuándo estuvieron ciertos bloques disponibles para su intervención como soporte de arte rupestre en el área. Ariadna Svoboda y Eduardo Julián Moreno presentan los resultados obtenidos a partir del análisis zooarqueológico de tres sondeos en relación a la explotación de recursos dulceacuícolas (peces, coipos y anátidos) y recursos terrestres (dasipódidos y guanaco) para el área del lago Colhué Huapi, Chubut. Cerrando la Sección, Melisa Rodríguez Oviedo da cuenta de los trabajos realizadas en el sitio La Rinconada Arriba ubicado en el Valle de Ambato, Catamarca, Argentina. Con esto vemos representada la arqueología regional de gran parte de la Argentina.

La Sección de Antropología Biológica presenta cinco trabajos. Rodrigo Zúñiga Thayer, Jorge Suby, Gustavo Flensborg y Leandro Luna analizan la variabilidad de la osteocondritis disecante en un conjunto de restos humanos de 26 individuos adultos pertenecientes a sociedades de cazadores-recolectores de Patagonia austral durante el Holoceno medio-tardío y su posible relación con la edad, el sexo, la dieta, la cronología y la procedencia geográfica. Tamara Giselle Navarro, Marcos Jannello, Marcos Jannello, Ignacio A. Cerda, Ignacio A. Cerda, Marien Béguelin, Marien Béguelin, Romina Vázquez y Romina Vázquez presenta un protocolo alternativo para la obtención de cortes delgados de muestras óseas humanas de sitios arqueológicos con el objetivo de aplicarlo al análisis microestructural. Pamela García Laborde, María Eugenia Conforti y Ricardo Anibal Guichón pretenden contribuir a la discusión sobre posibles estrategias que amplíen las prácticas profesionales de bioantropólogos y arqueólogos públicos promoviendo nuevas tramas de relaciones que articulen y reconfiguren a ambos enfoques en nuestro país. Daniela Alit Mansegosa, Pablo Sebastián Giannotti y Horacio Daniel Chiavazza presentan los resultados del análisis de indicadores de salud oral en una muestra de cráneos y mandíbulas recuperados en entierros secundarios de las Ruinas Jesuíticas de San Francisco, ubicadas en el Sitio Área Fundacional de la Ciudad de Mendoza. Cerrando la Sección Manuel Domingo D'Angelo del Campo, Pamela García Laborde, Luciano O. Valenzuela, Josefina M. B. Motti, Marilina Martucci, Patricia I. Palacio y Ricardo Aníbal Guichón reflexionan acerca de los avances técnicos 
de las últimas décadas y como estos han "incidido en el ámbito científico conllevando un aumento en la generación de nuevos conocimientos. Estos han permitido mejorar las comunicaciones y el acceso a la información. En estas condiciones, aparece una corriente global, el data sharing, que aboga por la libre puesta en disposición de los datos producto de las investigaciones científica".

En la Sección de Museología, Pamela Esther Degele, María Gabriela Chaparro, María Luz Endere presentan un trabajo que tiene como fin contrastar la normativa marco aplicable a las reservas naturales de la provincia de Buenos Aires con los usos sociales de los que es objeto el paisaje y patrimonio protegido por parte de diferentes grupos de interés. Por último para esta sección Julieta Barada analiza las transformaciones experimentadas en la iglesia del pueblo de Coranzulí (Puna de Jujuy) a través del estudio de las acciones realizadas por los pobladores sobre esta a lo largo del siglo $X X$ desde un enfoque histórico y patrimonial.

Cerrando este número presentamos los trabajos incluidos en la Sección Antropología Social. Maria Carman analiza críticamente los postulados de la corriente de pensamiento que ha servido de sustento a la militancia a favor del derecho animal: el antiespecismo. Paola Monkevicius analiza los sentidos públicos que se producen, transmiten y disputan acerca de la muerte (entendida como crimen racista) del activista senegalés Massar Ba por parte del colectivo conformado por inmigrantes africanos y afrodescendientes en Argentina. Adrián Koberwein reflexiona en torno al rol del conocimiento científico en el marco de los conflictos ambientales contemporáneos. En concreto, acerca de un conflicto reciente en torno a la reforma de la ley de bosques de la Provincia de Córdoba, Argentina. Sin duda tema ce interés central a la sociedad cordobesa contemporánea. Por último Milena Annecchiarico propone un análisis de la trayectoria del programa UNESCO "Ruta del Esclavo" en Argentina, que promueve la investigación sobre la esclavitud y la trata transatlántica de africanos esclavizados, las formas de resistencia y la valorización de los sitios de memoria y de las manifestaciones culturales de las comunidades afrodescendientes actuales.

Analizando sintéticamente lo relatado más arriba podemos aseverar que este primer número del año 2018 muestra una gran diversidad de temáticas en todas las secciones del mismo. Esperando que esto sea de interés y como siempre los invitamos a leer esta producción y nos despedimos hasta el próximo número.

Córdoba, 01 de Julio de 2018 